\title{
Inactivation of the E-Cadherin Gene in Sporadic Diffuse- Type Gastric Cancer
}

Jennifer J. Ascaño, M.S., Henry Frierson, Jr., M.D., Christopher A. Moskaluk, M.D., Ph.D., Jeffrey C. Harper, B.S., Franco Roviello, M.D., Charles E. Jackson, M.D., Wa'el El-Rifai, M.D., Ph.D., Carla Vindigni, M.D., Piero Tosi, M.D., Steven M. Powell, M.D.

Department of Medicine (JJA, JCH, WE, SMP) and Department of Pathology (HF, CAM), University of Virginia Health System, Charlottesville, Virginia; Istituto Policattedva di Scienze Chirurgiche (FR), Istituto di Anatomia Eistologia Patologica (CV, PT), and Universita' Degli Studi di Siena, Via della Scotte, Siena, Italy; and Henry Ford Hospital (CEJ), Detroit, Michigan

Loss of the cell adhesion molecule E-cadherin has been observed in a variety of human carcinomas, and germline E-cadherin mutations have been found in several familial cases of diffuse gastric cancer. We sought to determine the prevalence and nature of E-cadherin alterations in "sporadic" gastric carcinomas. We performed comprehensive sequencing of the coding region, loss of heterozygosity (LOH) analysis, and immunohistochemical protein expression determination on 40 sporadic gastric adenocarcinomas. In total, 7 of 25 diffusetype cancers harbored genetic alterations in the E-cadherin gene. Novel mutations predicted to significantly compromise protein function were found within 4 of these cancers, 2 of which harbored alterations resulting in biallelic inactivation of the gene product. Three diffuse cancers failed to amplify Exon 8 of E-cadherin, suggesting the presence of a homozygous abnormality. Notably, one germline E-cadherin mutation was also identified within these "sporadic" diffuse cancers. Significant gene mutations were not found in the 14 intestinal-type or histologically mixed cancer. Immunohistochemistry revealed aberrant or negative protein expression in seven diffuse-type tumors, four of which correlated with the genetic alterations. Both diffuse and intestinal-type tumors exhibited low rates of $\mathrm{LOH}$, suggesting that allelic loss at the locus is not a common mechanism for E-cadherin inactivation

Copyright (C) 2001 by The United States and Canadian Academy of Pathology, Inc.

VOL. 14, NO. 10, P. 942, 2001 Printed in the U.S.A.

Date of acceptance: May 25, 2001.

This work was supported by the R. Robert and Sally D. Funderburg Research Scholar Award in Gastric Biology related to cancer through the American Digestive Health Foundation and by NCI grant R01 (CA67900-06).

Address reprint requests to: Steven M. Powell, M.D., Department of Medicine, Division of Gastroenterology/Hepatology, University of Virginia, Health Sciences Center, Box 800708, Charlottesville, VA 22908-0708; email: smp8n@virginia.edu; fax: (804)-243-0491. during gastric tumorigenesis. Our observations suggest that inactivation of the E-cadherin gene occurs only in a subset of diffuse-type gastric cancers, as the majority of cases did not contain genetic alterations or identifiable protein abnormalities. Germline E-cadherin alterations, although rare, may underlie some diffuse gastric cancer cases that have important biologic and practical implications

KEY WORDS: Diffuse-type gastric cancer, E-cadherin, LOH, Sporadic gastric cancer.

Mod Pathol 2001;14(10):942-949

E-cadherin is a calcium-dependent epithelial cell adhesion molecule expressed at adherens junctions. Similar to the case with other members in the cadherin family, this transmembrane glycoprotein mediates homophilic cell-cell adhesion. The extracellular portion consists of five repeat domains, which create four calcium-binding sites that are essential for protein integrity (1). The protein's cytoplasmic domain complexes with actin filaments through the intracellular attachment proteins: $\alpha, \beta$, and $\gamma$ catenins.

Loss of E-cadherin homophilic cell-cell binding may result in the poorly differentiated phenotype of diffuse-type gastric carcinoma (2). E-cadherin mutations, affecting the extracellular domain, have been observed to alter cell shape toward a less epithelioid morphology and to also interfere with adhesion (3). Furthermore, cells with mutated E-cadherin demonstrate increased motility and altered organization of their actin cytoskeleton. Loss of E-cadherin expression has also been associated with metastasis, thereby providing evidence for its role as an invasion suppressor (4).

Loss of E-cadherin expression has been observed in many types of human cancer (4-6). Partial screening analyses have found somatic alterations of the E-cadherin gene $(\mathrm{CDH})$ in diffuse-type gas- 
tric cancer and in infiltrating lobular carcinoma of the breast, each of which exhibits striking loss of cell-cell adhesiveness (7-12). The majority of the somatic changes reported are skipped exons observed in cDNAs, mostly in Exons 8 and 9, which encode for the highly conserved extracellular calcium-binding domains essential for E-cadherin adhesiveness (13).

Germline mutations in the E-cadherin gene have been identified in several kindreds, manifesting as an autosomal-dominant inheritance of susceptibility toward the early development of diffuse-type gastric cancer (14-19). These mutations have been found in a variety of ethnic populations, including those of European, Japanese, Korean, and Maori descent. Germline mutations have been distributed over 14 of the 16 exons of E-cadherin (20).

In light of these observations, we sought to determine the prevalence and type of E-cadherin mutations in "sporadic" diffuse-type gastric carcinomas. Previous studies of sporadic gastric cancers have been limited in their analyses, with only partial screening of the coding region of E-cadherin or measuring only mRNA levels. We performed a comprehensive genetic screen of the entire coding region and the flanking intron-exon boundaries using genomic DNA of 25 diffuse type, 14 intestinal type, and one mixed case. We examined the tumors for allelic loss and loss of protein expression using immunohistochemical analysis. The prevalence of germline E-cadherin mutations among these cases was also determined.

\section{MATERIALS AND METHODS}

\section{Samples}

Forty surgically resected primary gastric adenocarcinoma and paired normal tissue specimens from patients were collected between 1994 to 1999 and frozen at the University of Virginia, Johns Hopkins University, and the Universita Degli Studi Di Siena, Italy in accordance with internal review board-approved protocols. The gastric tumors were microdissected to $>70 \%$ neoplastic cells for nucleotide extraction and sectioned for immunohistochemical analysis. Tumor-node-metastasis (TNM) staging of the resected cancers was assessed according to the consensus criteria adopted by the International Union Against Cancer (20). All four TNM stages were represented by the cases included in this study. The histopathology of these samples was assessed according to the Lauren classification, and 25 were classified as diffuse type, 14 as intestinal type, and 1 as a mixed type according to the Lauren classification. None of these cases fulfilled the Amsterdam criteria for hereditary nonpolyposis colon cancer. High molecular weight genomic DNA was extracted from tumor and normal samples by SDS/proteinase K digestion, phenol chloroform extraction, and ethanol precipitation as previously described (21).

\section{Mutational Analysis}

All 16 exons of the E-cadherin gene $(C D H 1)$ were amplified and sequenced for each of the samples using primers that have been published previously (9). Exons were amplified by PCR in a standard thermocycle reaction for 40 cycles. (Amplimers and detailed conditions are available from authors upon request.) PCR products were either column purified according to the manufacturer's protocol (Qiagen, Valencia, CA) or treated with exonuclease before directly sequencing using an amplimer and Thermosequenase, according to the manufacturer's protocol (Amersham, Piscataway, NJ). Products of sequencing reactions were then electrophoresed on a $6 \%$ denaturing polyacrylamide gel and subsequently visualized by autoradiography. Each mutation was confirmed by an independent PCR amplification and sequence analysis.

To further characterize a somatic mutation identified, an RT-PCR reaction was performed on diffuse-type cancer g71 total RNA that was isolated according to manufacturer's protocol (Qiagen, Valencia, CA). One microgram of RNA was used in first-strand synthesis in a reaction including hexamers and superscript (Gibco BRL, Rockville, MD), also according to manufacturer's protocol. The products were then amplified using primers within Exons 6 and 10 (E-cadherin Exon 6, forward: 5'GTCTGTCATGGAAGGTGCTC-3' and E-cadherin Exon 10 reverse: 5'-TCATTCACATCCCAGCACATC3 ') in a standard thermocycle reaction of 40 cycles with an annealing temperature of $55^{\circ} \mathrm{C}$. These products were then purified and sequenced as described above.

\section{LOH Analysis}

Loss of heterozygosity was assessed for the 40 tumors using six polymorphic microsatellite markers on chromosome 16q near the E-cadherin gene. The markers included D16S752, D16S3043, D16S3019, D16S3083, D16S402, and D16S402. LOH analysis was performed by using an end-oligonucleotide labeling method as described previously (22). In brief, the forward primer was end-labeled with $\left[\gamma_{-}{ }^{32} \mathrm{P}\right]$ ATP in a tyrosine kinase reaction incubated at $37^{\circ} \mathrm{C}$ for 18 minutes and subsequently heat inactivated at $68^{\circ} \mathrm{C}$ for 5 minutes. The primer was then purified using a G-25 Microspin column according to the manufacturer's recommendation (Amersham Pharmacia Biotech, Piscataway, NJ) The reverse unlabeled primer was then added and 
used in a thermocycle reaction. Optimal PCR conditions were obtained for each marker, and amplification was performed for each tumor and normal DNA sample pair for subsequent electrophoresing on $7 \%$ acrylamide gels.

Normal samples with two distinctly sized alleles at a particular marker were termed "informative." Each informative tumor and normal DNA was then compared with respect to allelic band intensity using a PhosphorImager (Molecular Dynamics, Sunnyvale, CA). A comparative ratio was then produced by dividing the tumor allelic ratio by the normal allelic ratio. A comparative ratio $\geq 1.5$ was considered to represent allelic loss, and one of $<1.5$, to represent allelic retention. Samples with only one allelic band were considered noninformative. A tumor that demonstrated a differently sized allele compared with its respective normal sample was scored as microsatellite instable.

\section{Immunohistochemical Staining}

Immunohistochemistry was performed on frozen sections of 36 available samples (14 intestinal type, 21 diffuse type, and 1 mixed). The monoclonal antibody HECD-1 (Zymed Laboratories, South San Francisco, CA), directed against the $\mathrm{N}$-terminal portion of E-cadherin, was used in a 1:200 dilution of a $10-\mu \mathrm{g} / \mathrm{mL}$ stock solution. The monoclonal antibody AEC (clone 36, Transduction Laboratories, Lexington, $\mathrm{KY}$ ), directed against the $\mathrm{C}$-terminal portion of E-cadherin, was used in a 1:2000 dilution of a 250 $\mathrm{ug} / \mathrm{mL}$ stock solution. Epitope retrieval was used for both antibodies: $4-\mu \mathrm{m}$ histologic sections on glass slides were immersed in $10 \mathrm{~mm}$ citrate buffer,
pH 6.0, and heated in a microwave oven at a high setting (Emerson, $1200 \mathrm{~W}$ ). Evaporated liquid was replenished at 5-minute intervals for a total of 20 minutes. Antibody was applied to the histologic sections for 1 hour at room temperature, which was followed by the avidin-biotin-peroxidase staining technique (Vectastain Elite ABC kit, Vector Laboratories, Burlingame, CA) and incubation with 3,3' diaminobenzidine tetrahydrochloride. The sections were counterstained with hematoxylin. Staining was classified as positive (predominant surface membrane immunoreactivity), aberrant (cytoplasmic only), and negative (complete absence). In cases classified as positive and aberrant, staining was observed in the majority of tumor cells.

\section{RESULTS}

\section{Mutational Analysis}

All 16 coding exons of the E-cadherin gene, including each flanking exon/intron boundary, were successfully amplified in all samples except for three diffuse-type cancers (g160, g93, and g108) that failed to amplify Exon 8 . The integrity of these three DNA samples was observed in the successful amplification of the remaining 15 exons of the E-cadherin gene. Multiplex PCR was not possible for this exon because of high magnesium requirements, and RNA was not available on these cases for RT-PCR analysis.

Nucleotide sequencing analysis of amplified PCR products revealed novel mutations in four diffusetype cases (Table 1.) These mutations are predicted

TABLE 1. Summary of E-Cadherin Gene (CDH1) and Protein Abnormalities

\begin{tabular}{|c|c|c|c|c|c|c|c|}
\hline \multirow{2}{*}{$\begin{array}{c}\text { Case } \\
\text { Designator }\end{array}$} & \multirow{2}{*}{ Histology } & \multicolumn{3}{|c|}{ Nucleotide Changes } & \multirow{2}{*}{$\mathrm{LOH}^{a}$} & \multicolumn{2}{|c|}{ Immunohistochemistry } \\
\hline & & Intron/Exon & Mutation & Result & & HECD-1 & AEC \\
\hline g74 & $\mathrm{D}$ & Intron 7 & $\begin{array}{l}\text { ag/AGT to } \\
\mathrm{cg} / \mathrm{AGT}\end{array}$ & $\begin{array}{l}\text { Exon } 8 \\
\text { skipping }\end{array}$ & NA & + (focally) & + \\
\hline g93 & $\mathrm{D}$ & Exon 8 & & $\begin{array}{l}\text { Will not } \\
\text { amplify }\end{array}$ & $0 / 1$ & + & + \\
\hline g108 & $\mathrm{D}$ & Exon 8 & & $\begin{array}{l}\text { Will not } \\
\text { amplify }\end{array}$ & $0 / 0$ & - & - \\
\hline g160 & $\mathrm{D}$ & Exon 8 & & $\begin{array}{l}\text { Will not } \\
\text { amplify }\end{array}$ & $0 / 2$ & + & + \\
\hline g24 & $\mathrm{D}$ & Exon 9 & $\begin{array}{l}\mathrm{C} \text { insertion } \\
\text { at } 1208\end{array}$ & $\begin{array}{l}\text { Premature } \\
\text { stop at } \\
\text { Codon } 418\end{array}$ & $1 / 1$ & + & - \\
\hline g112 & $\mathrm{D}$ & Exon 9 & $\begin{array}{l}\text { 5-bp } \\
\text { insertion } \\
\text { at } 1216\end{array}$ & $\begin{array}{l}\text { Premature } \\
\text { stop at } \\
\text { Codon } 418\end{array}$ & $1 / 2$ & + & $\begin{array}{c}\text { aberrant } \\
\text { cytoplasmic }\end{array}$ \\
\hline g71 & $\mathrm{D}$ & Exon 12 & g1849a & $\begin{array}{l}\text { A to } \mathrm{T} \text { in } \\
\text { conserved } \\
\mathrm{DAD} \text { at } \\
\text { Codon } 617\end{array}$ & $0 / 2$ & + & + \\
\hline g8 & $\mathrm{D}$ & & & & $0 / 0$ & + & - \\
\hline g30 & mixed & & & & $1 / 2$ & $\begin{array}{c}\text { mixed } \\
(+ \text { and }-)\end{array}$ & - \\
\hline g181 & D & & & & $1 / 2$ & + & - \\
\hline
\end{tabular}

${ }^{a}$ Loss/informative.

$\mathrm{D}$, diffuse type; mixed, loss in diffuse regions and no loss in intestinal regions; NA, not available. 
to significantly alter the protein product. Although the number of cases with E-cadherin gene and expression alterations was small, no obvious association with clinicopathologic parameters was found as both early (Stage II) cases and more advanced (Stage III) cases harbored changes in this gene and gene product.

A 1-base pair insertion was found at Codon 403 of Exon 9 in Cancer g24, and this is predicted to result in a premature stop in Codon 418 in Exon 9 (Fig. 1A.) For Cancer g112, a 5-bp insertion at position 1216 of Exon 9 was observed, also predicted to result in a premature stop at Codon 418. These mutations were not seen in the corresponding noncancerous tissue, thus confirming the somatic nature of the alterations.

A single base pair substitution was found within Exon 12 of Cancer g71 in both the normal and neoplastic tissue DNA, revealing the germline nature of this alteration (Fig. 1B.) This G to A transition at Nucleotide 1849 of the gene is predicted to result in a single amino acid substitution of an alanine for a threonine at Codon 617, thus altering a conserved calcium-binding DAD motif.

A splice acceptor site mutation consisting of an A to $C$ transversion at the -2 position of the Intron 7/Exon 8 boundary was observed for Cancer g74. As normal tissue was limited, neither DNA nor RNA from noncancerous tissue was available for this case, and we were unable to determine the somatic or germline nature of this mutation. An RT-PCR reaction of RNA extracted from this tumor revealed the presence of an aberrantly spliced mRNA of a shorter length as well as the presence of a normal, properly spliced fragment (Fig. 2A.) The aberrant
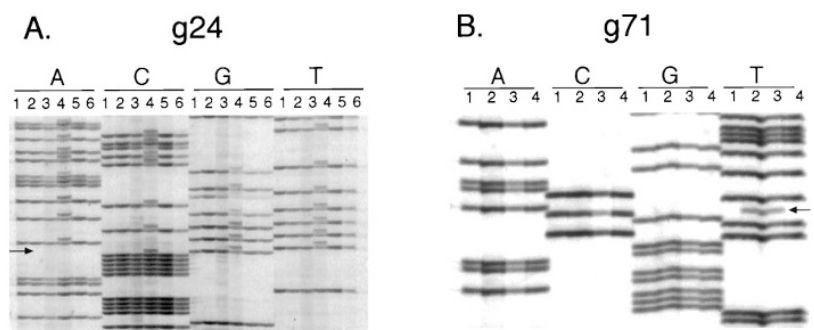

FIGURE 1. Mutational analysis of the E-cadherin gene $(C D H 1)$. The coding region of the E-cadherin gene was analyzed by DNA sequencing of gastric carcinomas. Sequence reactions were grouped by nucleotide to aid in the identification of any aberrations. A, Exon 9, including the intron-exon boundaries, of five representative diffuse-type cases is displayed. Lanes 4 and 5 represent DNA extracted from tumor and noncancerous tissue from diffuse-type Case g24, respectively. A somatic C insertion in Codon 403 of Exon 9 (Lane 4) predicted to result in a premature stop in Codon 418 is observed. B, Exon 12 of three diffusetype cases. Lanes 2 and 3 represent DNA extracted from tumor and noncancerous tissue from diffuse-type Case g71, respectively. A G to A transition at Position 1849 is observed in both the normal and cancerous tissue DNA, which is predicted to result in a single amino acid substitution of an alanine to a threonine in Codon 617 .

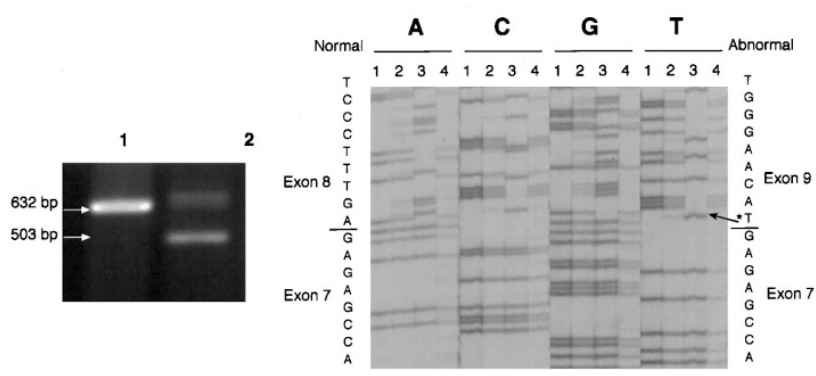

FIGURE 2. Analysis of diffuse-type cancer G74. A, RT-PCR analysis. A 639-bp cDNA fragment spanning from Exon 6 to 10 of the E-cadherin gene is shown here. Lanes 1 and 2 represent mRNA extracted from normal colon tissue and a tumor from g74, respectively. The properly spliced fragment is seen in cancer g74 (Lane 2) as well as a shorter, improperly spliced fragment. B, Sequence analysis of the cDNA fragment. Sequence reactions were grouped by nucleotide as in Figure 1. Lanes 1 and 4 represent the normally spliced cDNA fragment from normal colon tissue and diffuse-type cancer g108, respectively. Lanes 2 and 3 represent the properly spliced and improperly spliced cDNA fragment of cancer g74, respectively. The improperly spliced cDNA fragment is shown here to have skipped Exon 8.

fragment was sequenced and found to have skipped Exon 8 (Fig. 2B).

Genetic alterations without obvious functional importance were also observed. The intestinal-type Case g154 carried a missense G to A transition in Position 1774, which is predicted to result in a single amino acid substitution of an alanine to a threonine at Codon 592 of Exon 12. Additionally, silent polymorphisms and intronic changes were observed in 18 cases: 12 diffuse type and 6 intestinal type (Table 2.)

\section{LOH Analysis}

Allelic loss was determined using six polymorphic microsatellite markers straddling the E-cadherin gene locus at 16q22.1. Twenty-four of 26 (92.3\%) diffuse-type and 13 of 14 (92.8\%) intestinal-type cases were informative for at least one marker. Seven of $24(29.2 \%)$ informative diffuse-type and 6 of $13(46.2 \%)$ informative intestinal-type cases exhibited loss of heterozygosity (LOH) at the E-cadherin locus. Only one diffuse-type case (g155) and one intestinal-type case (g116) consistently showed LOH for all of their respective informative markers. Six diffuse-type cases (g24, g30, g112, g126, g181, and g204) and intestinal-type case g51 only showed loss for one of two informative markers. Two intestinal-type cases (g147 and g170) showed loss in one of three informative markers, and two intestinal type cases (g154 and g165) showed loss in one of four informative markers. Microsatellite instability was observed in diffusetype Case g126 for one marker, Case g204 for two 


\begin{tabular}{|c|c|c|c|c|c|c|c|}
\hline \multirow{2}{*}{$\begin{array}{c}\text { Case } \\
\text { Designator }\end{array}$} & \multirow{2}{*}{ Histology } & \multicolumn{3}{|c|}{ Nucleotide Changes } & \multirow{2}{*}{$\mathrm{LOH}^{a}$} & \multicolumn{2}{|c|}{ Immunohistochemistry } \\
\hline & & Intron/Exon & Change & Result & & HECD-1 & AEC \\
\hline g42 & I & Intron 1 & $\mathrm{t}+6 \mathrm{~g}$ & NAD & $0 / 1$ & + & NA \\
\hline g170 & & & (het) & & $1 / 2$ & + & NA \\
\hline g8 & $\mathrm{D}$ & Intron 4 & $\begin{array}{l}\mathrm{c}+10 \mathrm{~g} \\
\text { (hom) }\end{array}$ & NAD & $0 / 0$ & + & - \\
\hline g147 & I & & & & $1 / 3$ & + & + \\
\hline g151 & & & & & $0 / 5$ & + & + \\
\hline g154 & & & & & $0 / 3$ & + & + \\
\hline g79 & $\mathrm{D}$ & Intron 4 & $c+10 g$ & NAD & $1 / 1$ & + & + \\
\hline g133 & & & (het) & & $0 / 1$ & NA & NA \\
\hline g51 & $\mathrm{I}$ & & & & $1 / 1$ & + & + \\
\hline g74 & $\mathrm{D}$ & Exon 12 & $\mathrm{c} 1744 \mathrm{t}$ & $\mathrm{L}$ to $\mathrm{L}$ at Codon 582 & NA & $\begin{array}{c}+ \\
\text { (focally) }\end{array}$ & + \\
\hline g130 & I & Exon 12 & $\mathrm{c} 1896 \mathrm{t}$ & $\mathrm{H}$ to $\mathrm{H}$ at Codon 632 & $0 / 3$ & + & + \\
\hline g155 & $\mathrm{D}$ & Exon 13 & $\begin{array}{l}\text { c2076t } \\
\text { (hom) }\end{array}$ & A to $\mathrm{A}$ at Codon 692 & $2 / 2$ & + & + \\
\hline g5 & $\mathrm{D}$ & Exon 13 & $\mathrm{c} 2076 \mathrm{t}$ & A to A at Codon 692 & $0 / 1$ & + & + \\
\hline g24 & & & (het) & & $1 / 1$ & + & - \\
\hline g30 & & & & & $1 / 2$ & mixed & - \\
\hline g67 & & & & & $0 / 0$ & + & + \\
\hline g149 & I & & & & $0 / 3$ & + & NA \\
\hline g116 & & & & & $1 / 1$ & + & + \\
\hline
\end{tabular}

${ }^{a}$ Loss/informative.

D, diffuse type; het, heterozygous; hom, homozygous; NAD, not able to be determined.

markers, and intestinal-type Case g165 for three markers; all three cases also showed LOH for one of one informative marker.

\section{Immunohistochemistry}

Cell membrane-positive staining using each of the antibodies was observed for all 14 of the pure intestinal-type and 15 of the 22 diffuse-type tumors that were immunostained. A representative example is shown (Fig. 3A.) Aberrant or complete loss of expression when stained with one or both antibodies was apparent in the one mixed-type cancer and in six of the diffuse-type cancers, four of which coincided with genetic alterations (see Table 1.) Diffuse-type adenocarcinoma g24 stained positive with the $\mathrm{N}$-terminal antibody yet revealed complete loss of expression when stained with the C-terminal antibody (Fig. 3C, D). Immunohistochemical staining of Case g112 resulted in aberrant (cytoplasmic) staining, with the antibody recognizing the C-terminus of E-cadherin (Fig. 3B), whereas the antibody to the $\mathrm{N}$-terminus protein showed surface membrane staining (data not shown). Diffuse-type Cancer g74 showed focally positive expression with only the $N$-terminal antibody. Diffuse-type Case g108 exhibited complete loss of protein expression with each antibody.

The remaining three diffuse-type gastric tumors with protein staining abnormalities were not found to contain any genetic alterations. Diffuse-type cancers g8 and g181 resulted in positive membrane staining when using the $N$-terminal antibody but complete loss of expression with the C-terminal

\section{A. $\quad$ 666 (positive)}

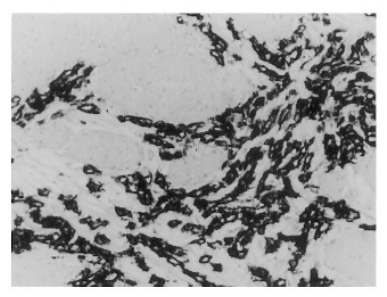

C. $\quad \mathbf{2 4}$ (positive)

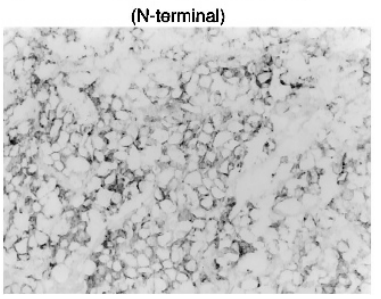

B. $\quad \mathbf{g 1 1 2}$ (aberrant)

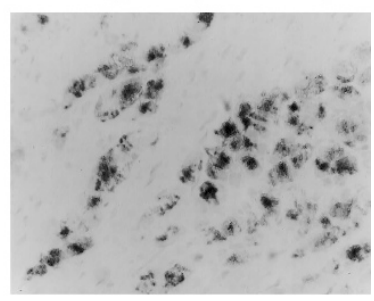

D. $\quad$ 24 (negative)

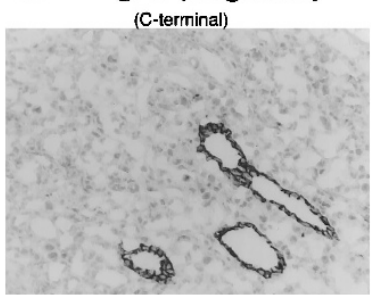

FIGURE 3. Immunohistochemical analysis. Two antibodies were used: HECD- 1 to detect the presence of the $N$-terminal extracellular domain and AEC to detect the presence of the C-terminal cytoplasmic domain of the E-cadherin protein. A, Membrane staining with AEC in diffuse-type Case g66. B, Aberrant cytoplasmic staining with AEC in diffuse-type Case g112. C, Membrane staining with HECD-1 in diffusetype Case g24. D, Absence of staining with AEC in diffuse-type Case g24. An internal positive control of a normal gland with membrane staining is also observed.

antibody. Mixed case g30 showed areas with loss of E-cadherin protein expression in the diffuse component of the tumor upon staining with the $N$-terminal antibody, whereas the intestinal component exhibited surface membrane immunoreactivity. No staining was seen for this case using the AEC antibody, which recognizes the C-terminal domain of E-cadherin. 


\section{DISCUSSION}

The prevalence and type of E-cadherin gene alterations, biallelic inactivation, and changes of protein expression in sporadic gastric cancer were determined in this study. Our findings suggest that inactivation of the E-cadherin gene and loss of normal E-cadherin protein is involved in only a minority of "sporadic" diffuse-type carcinomas. Significant genetic alterations were not found in any of the 14 intestinal-type or mixed-type gastric cancers, but were found in 7 out of 25 diffuse-type cancers. Similarly, protein abnormalities were not observed in any of the 14 intestinal-type, but were seen in 7 out of the 22 diffuse-type cancers analyzed. Thus, the majority of diffuse-type tumors (68\%) and all of the intestinal-type gastric cancers had no detectable abnormalities in either the gene or its protein expression.

The four novel E-cadherin gene $(\mathrm{CDH} 1)$ nucleotide alterations identified are predicted to significantly alter the gene product function. Two of these alterations are somatic changes, whereas one is a germline mutation, and the somatic or germline status for the fourth mutation was not able to be determined. In contrast, only one somatic gene alteration was found in an intestinal-type cancer and its functional importance is uncertain. Nineteen diffuse-type cases contained a normal E-cadherin gene sequence, suggesting that E-cadherin mutation may be a relatively infrequent event in the development of diffuse-type carcinomas.

Of the four diffuse-type cancers harboring E-cadherin mutations, two cases have suffered biallelic inactivation, consistent with Knudsen's classic two-hit model of tumorigenesis. Diffuse-type Cancers g24 and g112 carried somatic mutations in Exon 9, predicted to result in a truncated protein containing only the extracellular domain. Immunohistochemical analysis of g24 supported the predicted truncation of the protein because only the extracellular amino terminal region could be detected (see Fig. 3, C-D). Interestingly, Case g112, which harbored a 5-bp insertion predicted to produce a similar truncated protein as g24, yet did not consistently show LOH as g24, exhibited a distinct cytoplasmic staining pattern using the C-terminal antibody (see Fig. 3B). This particular staining pattern has also been seen in calcium-depleted conditions in which E-cadherin-mediated cell-cell adhesion was lost (23). Handschuh et al. (3) observed this pattern of staining in cell lines that harbored mutations in Exons 8 and 9. Thus, the unique staining pattern observed in g112 might reflect the presence of an altered E-cadherin protein that has either been removed from the membrane or incorrectly processed within the Golgi apparatus. Recently, selective degradation and proteolytic cleavage of the E-cadherin protein has been noted, with the resulting fragment being distinct from the soluble form of the protein, remaining associated with cytoplasmic $\beta$-catenin $(24,25)$. More important, the presence of these aberrantly expressed proteins, in conjunction with the somatic alterations observed, supports the hypothesis that the E-cadherin locus has undergone biallelic inactivation for these two cases.

On the other hand, two diffuse-type cancers g71 and g74 did not appear to contain biallelic E-cadherin inactivation. They harbored an E-cadherin gene mutation in one allele, whereas the other allele appeared to remain unaltered on several levels of genetic and immunohistochemical analyses. Cancer g71 carried a germline missense mutation predicted to result in a single amino acid substitution in a conserved DAD motif in Exon 12, which is a conserved calciumbinding site. This mutation did not coincide with $\mathrm{LOH}$ or any protein abnormalities. This patient was a woman of African-American descent and was 64 years of age when diagnosed with a Stage IIIA cancer. A review of the family history for this patient revealed no other family members with gastric cancer, although the medical records were scant and the patient was deceased. Cancer g74 had an alteration in a conserved splice acceptor site of Intron 7 , which is predicted to affect the extracellular domain of the protein. Similar mutations have been reported previously $(7,11,26)$ and demonstrated to result in Exon 8 skipping, as we observed (Fig. 2A,B). The presence of the properly spliced mRNA suggests that the second allele has remained unaffected.

Three diffuse-type cases (g93, g160, and g108) appear to contain genetic alterations involving Exon 8 and its flanking introns. Our results suggest the presence of a gross homozygous genetic alteration, such as a large insertion or deletion, within these cancers. Cancer g108 revealed a complete absence of E-cadherin protein expression providing additional evidence of a significant change in the integrity of this gene's protein.

Immunohistochemical analysis demonstrated the presence of a properly expressed membranous protein in all of the intestinal-type and the majority of the diffuse-type cancer. Of the seven diffuse-type cancers with abnormalities, three exhibited loss of E-cadherin expression and did not harbor any identifiable nucleotide alteration. Analysis of cancers g8 and g181 suggests the loss of the cytoplasmic domain of the E-cadherin protein, and although g181 did show LOH, no genetic aberrations could be identified to explain this loss (Table 1). The diffuse part of mixed case g30, showed complete loss of protein expression and allelic loss (Table 1). The fact that nucleotide changes were not observed in the coding region of some of these cases with abnormal protein expression may reflect the dysregu- 
lation of gene expression. Complete loss of protein expression has been observed to be associated with hypermethylation of $\mathrm{CpG}$ islands in the promoter of the E-cadherin gene $(27,28)$. Complete loss of expression has also been postulated to be the result of the silencing effects of a yet-to-be characterized cisor trans-acting factor (29).

In general, allelic loss was noted only in a minority of cases. Interestingly, diffuse-type cancers in our study showed a significantly lower rate of allelic loss $(29.2 \%)$ compared with the intestinal-type tumors (46\%). Indeed, significant LOH was not noted at the E-cadherin loci in previous comprehensive surveys $(22,30)$. Furthermore, a recent molecular study on gastric cancers carrying germline mutations in the E-cadherin gene consistently demonstrated an absence of $\mathrm{LOH}$ at this locus and observed that methylation of the promotor was commonly noted in the wild-type allele (28). Thus, allelic loss at this locus may not be a common mechanism for inactivation of E-cadherin.

In summary, our results suggest that inactivation of E-cadherin is an infrequent event in the development of sporadic gastric cancer, even in the diffuse-type. Thus, critical alterations underlying the majority of diffuse-type gastric carcinomas remain to be characterized. Other molecules directly involved in E-cadherin-mediated cell-cell adhesion complex such as the intracellular attachment proteins $\alpha, \beta$, and $\gamma$ catenins may be subject to targeted alteration. Previous studies have reported decreased $\alpha$-catenin expression in gastric cancers (31-35). Whether other molecules in the same biochemical pathway as E-cadherin or other yet-to-bediscovered signaling pathways are altered in diffuse gastric cancers remains to be determined.

Acknowledgments: We are grateful to Kathy Romans and Stanley R. Hamilton for their assistance in sample collection.

\section{REFERENCES}

1. Overduin M, Harvey TS, Bagby S, Tong KI, Yau P, Takeichi M, et al. Solution structure of the epithelial cadherin domain responsible for selective cell adhesion [see comments]. Science 1995;267:386-9.

2. Mayer B, Johnson JP, Leitl F, Jauch KW, Heiss MM, Schildberg FW, et al. E-cadherin expression in primary and metastatic gastric cancer: down-regulation correlates with cellular dedifferentiation and glandular disintegration. Cancer Res 1993;53:1690-5.

3. Handschuh G, Candidus S, Luber B, Reich U, Schott C, Oswald S, et al. Tumour-associated E-cadherin mutations alter cellular morphology, decrease cellular adhesion and increase cellular motility. Oncogene 1999;18:4301-12.

4. Takeichi M. Cadherins in cancer: implications for invasion and metastasis. Curr Opin Cell Biol 1993;5:806-11.

5. Birchmeier W, Behrens J. Cadherin expression in carcinomas: role in the formation of cell junctions and the prevention of invasiveness. Biochim Biophys Acta 1994;1198:11-26.
6. Mareel M, Bracke M, Van Roy F. Invasion promoter versus invasion suppressor molecules: the paradigm of E-cadherin. Mol Biol Rep 1994;19:45-67.

7. Becker KF, Atkinson MJ, Reich U, Becker I, Nekarda H, Siewert JR, et al. E-cadherin gene mutations provide clues to diffuse type gastric carcinomas. Cancer Res 1994;54: 3845-52.

8. Becker KF, Hofler H. Frequent somatic allelic inactivation of the E-cadherin gene in gastric carcinomas. J Natl Cancer Inst 1995;87:1082-4.

9. Berx G, Cleton-Jansen AM, Nollet F, de Leeuw WJ, van de Vijver M, Cornelisse C, et al. E-cadherin is a tumour/invasion suppressor gene mutated in human lobular breast cancers. EMBO J 1995;14:6107-15.

10. Muta H, Noguchi M, Kanai Y, Ochiai A, Nawata H, Hirohashi $\mathrm{S}$. E-cadherin gene mutations in signet ring cell carcinoma of the stomach. Jpn J Cancer Res 1996;87:843-8.

11. Machado JC, Soares P, Carneiro F, Rocha A, Beck S, Blin N, et al. E-cadherin gene mutations provide a genetic basis for the phenotypic divergence of mixed gastric carcinomas. Lab Invest 1999;79:459-65.

12. Tamura G, Sakata K, Nishizuka S, Maesawa C, Suzuki Y, Iwaya $\mathrm{T}$, et al. Inactivation of the E-cadherin gene in primary gastric carcinomas and gastric carcinoma cell lines. Jpn J Cancer Res 1996;87:1153-9.

13. Berx G, Becker KF, Hofler H, van Roy F. Mutations of the human E-cadherin (CDH1) gene. Hum Mutat 1998;12:22637.

14. Guilford P, Hopkins J, Harraway J, McLeod M, McLeod N, Harawira $\mathrm{P}$, et al. E-cadherin germline mutations in familial gastric cancer. Nature 1998;392:402-5.

15. Gayther SA, Gorringe KL, Ramus SJ, Huntsman D, Roviello F, Grehan N, et al. Identification of germ-line E-cadherin mutations in gastric cancer families of European origin. Cancer Res 1998;58:4086-9.

16. Shinmura K, Kohno T, Takahashi M, Sasaki A, Ochiai A, Guilford P, et al. Familial gastric cancer: clinicopathological characteristics, RER phenotype and germline p53 and E-cadherin mutations. Carcinogenesis 1999;20:1127-31.

17. Keller G, Vogelsang H, Becker I, Hutter J, Ott K, Candidus S, et al. Diffuse type gastric and lobular breast carcinoma in a familial gastric cancer patient with an E-cadherin germline mutation. Am J Pathol 1999;155:337-42.

18. Yoon KA, Ku JL, Yang HK, Kim WH, Park SY, Park JG. Germline mutations of E-cadherin gene in Korean familial gastric cancer patients. J Hum Genet 1999;44:177-80.

19. Richards FM, McKee SA, Rajpar MH, Cole TR, Evans DG, Jankowski JA, et al. Germline E-cadherin gene (CDH1) mutations predispose to familial gastric cancer and colorectal cancer. Hum Mol Genet 1999;8:607-10.

20. Sobin LH, Wittekind $\mathrm{CH}$, editors. International Union Against Cancer (UICC): TNM classification of malignant tumours. 5th ed. New York: John Wiley; 1997.

21. Powell SM, Harper JC, Hamilton SR, Robinson CR, Cummings OW. Inactivation of Smad4 in gastric carcinomas. Cancer Res 1997;57:4221-4.

22. Yustein AS, Harper JC, Petroni GR, Cummings OW, Moskaluk CA, Powell SM. Allelotype of gastric adenocarcinoma. Cancer Res 1999;59:1437-41.

23. Shore EM, Nelson WJ. Biosynthesis of the cell adhesion molecule uvomorulin (E-cadherin) in Madin-Darby canine kidney epithelial cells. J Biol Chem 1991;266:19672-80.

24. Bush KT, Tsukamoto T, Nigam SK. Selective degradation of E-cadherin and dissolution of E-cadherin-catenin complexes in epithelial ischemia. Am J Physiol Ren Physiol 2000; 278:F847-52.

25. Steinhusen U, Weiske J, Badock V, Tauber R, Bommert K, Huber O. Cleavage and shedding of E-cadherin after induction of apoptosis. J Biol Chem 2001;16:4972-80. 
26. Berx G, Cleton-Jansen AM, Strumane K, de Leeuw WJ, Nollet $\mathrm{F}$, van Roy F, et al. E-cadherin is inactivated in a majority of invasive human lobular breast cancers by truncation mutations throughout its extracellular domain. Oncogene 1996; 13:1919-25.

27. Tamura G, Yin J, Wang S, Fleisher AS, Zou T, Abraham JM, et al. E-cadherin gene promoter hypermethylation in primary human gastric carcinomas. J Natl Cancer Inst 2000;92:569-73.

28. Grady WM, Willis J, Guilford PJ, Dunbier AK, Toro TT, Lynch $\mathrm{H}$, et al. Methylation of the $\mathrm{CDH} 1$ promoter as the second genetic hit in hereditary diffuse gastric cancer. Nat Genet 2000;26:16-7.

29. Ji X, Woodard AS, Rimm DL, Fearon ER. Transcriptional defects underlie loss of E-cadherin expression in breast cancer. Cell Growth Differ 1997;8:773-8.

30. Schneider BG, Pulitzer DR, Brown RD, Prihoda TJ, Bostwick DG, Saldivar V, et al. Allelic imbalance in gastric cancer: an affected site on chromosome arm 3p. Genes Chromosom Cancer 1995;13:263-71.

31. Jawhari AU, Noda M, Farthing MJ, Pignatelli M. Abnormal expression and function of the E-cadherin-catenin com- plex in gastric carcinoma cell lines. Br J Cancer 1999;80: 322-30.

32. Ohene-Abuakwa Y, Noda M, Perenyi M, Kobayashi N, Kashima K, Hattori T, et al. Expression of the E-cadherin/ catenin (alpha-, beta-, and gamma-) complex correlates with the macroscopic appearance of early gastric cancer. J Pathol 2000;192:433-9.

33. Yu J, Ebert MP, Miehlke S, Rost H, Lendeckel U, Leodolter A, et al. Alpha-catenin expression is decreased in human gastric cancers and in the gastric mucosa of first degree relatives. Gut 2000;46:639-44.

34. Xiangming C, Hokita S, Natsugoe S, Tanabe G, Baba M, Takao S, et al. Cooccurrence of reduced expression of alphacatenin and overexpression of p53 is a predictor of lymph node metastasis in early gastric cancer. Oncology 1999;57: 131-7.

35. Matsui S, Shiozaki H, Inoue M, Tamura S, Doki Y, Kadowaki $\mathrm{T}$, et al. Immunohistochemical evaluation of alpha-catenin expression in human gastric cancer. Virchows Arch 1994; 424:375-81. 